\title{
The Fracture and Fatigue Properties of Cast Irons Used for Trunk Mains in the Water Industry
}

\author{
H Mohebbi, D A Jesson, M J Mulheron and P A Smith \\ Faculty of Engineering and Physical Sciences \\ University of Surrey \\ Guildford, Surrey GU2 7XH UK
}

Corresponding author e-mail: $\underline{\text { D.Jesson@ } @ \text { surrey.ac.uk }}$

\begin{abstract}
In order to assess the remaining life of cast iron assets in the water sector, an understanding of their fracture and fatigue characteristics is necessary. The present work is concerned with the toughness and Paris crack growth behaviour of cast iron materials with a range of microstructures, taken from trunk mains currently in service. When considered with other data from the literature, the results from the present study enable the range of fatigue crack growth behaviour likely to be seen in service to be quantified. Calculations of fatigue life based on integration of the Paris law are then carried out and compared with previously published data for samples from cast iron distribution mains. The results from these investigations support the development of asset management tools for use in the water industry.
\end{abstract}

Keywords: Cast iron; Microstructure; $S-N$ curves; Fractography 


\section{Introduction}

Cast iron is a material that still has significant usage in the water industry. In the context of the United Kingdom, although cast iron pipes are being phased out of distribution and mains systems, a significant portion of current pipe networks are comprised of an aging cast iron infrastructure that can be up to 150 years old. This cast iron infrastructure is deteriorating at different rates, e.g. $[1,2]$, which are linked to the geology and other localised conditions. The problem is complicated further by the diversity in production quality as well as the range of diameters and wall thicknesses used. In order to develop a rehabilitation or replacement strategy for the industry, it is important not only to understand the mechanisms by which a pipe can fail, but also to use this understanding to develop tools for asset management. To better model these mechanisms, and their contribution to service failures, an understanding of the initiation and propagation of cracks is necessary. For example, sub-critical cracks can originate from inherent defects present ab initio from casting, may be generated during installation or could arise during time in service. If these hypotheses are true, then any information on the factors influencing fatigue behaviour and the rate of crack growth is of relevance. Although the literature regarding the fatigue behaviour of grey cast iron is limited, a considerable range of behaviour is apparent from previous work [3-6]. These variations are thought to be consistent with microstructural differences between the grey cast irons tested in these studies. In one study [6], fracture toughness and fatigue data are presented for a number of cast irons and, for one material in particular, crack growth under fatigue loading is associated with a higher applied stress intensity factor range than for any other cast iron materials reported in the literature. To understand whether fatigue is an issue in the water industry and to inform asset management, a more systematic comparison of the behaviour of a representative variety of cast irons over a range of fatigue loading conditions is required than is currently available. 
In the present work the propagation of fatigue cracks in samples of different types of cast iron were studied in order to investigate the role of the microstructure on the fatigue behaviour of cast iron trunk mains. The structure of the paper is as follows. In the next section the test materials and test methods are described. Following this, results are presented relating to the microstructure and fracture and fatigue behaviour, with supporting fractography. Finally, the implications for service life are considered, with reference to published data for specimens from cast iron distribution mains.

\section{Experimental Methods}

\subsection{Range of samples tested:}

Examples of cast iron pipe were sourced from four water mains which had failed in-service.

Details of the nominal pipe diameter and wall thickness are given in Table 1.

Table 1 Details of the pipes investigated in the present study

\begin{tabular}{|c|c|c|c|}
\hline & $\begin{array}{c}\text { Nominal Wall thickness/ } \\
\mathbf{m m}\end{array}$ & \multicolumn{2}{|c|}{ Nominal Diameter/ } \\
\cline { 3 - 4 } & 28 & inches & $\mathbf{m}$ \\
\hline Pipe A & 32 & 42 & 1.07 \\
\hline Pipe B & 22 & 30 & 0.76 \\
\hline Pipe C & 28 & 48 & 1.22 \\
\hline Pipe D & 21 & 0.533 \\
\hline
\end{tabular}

Three large plates (approximately $450 \mathrm{~mm}$ by $450 \mathrm{~mm}$ ) were cut from each pipe and the required test specimens were machined from these plates (Fig. 1) using the methodology described in sections 2.2 and 2.3 .
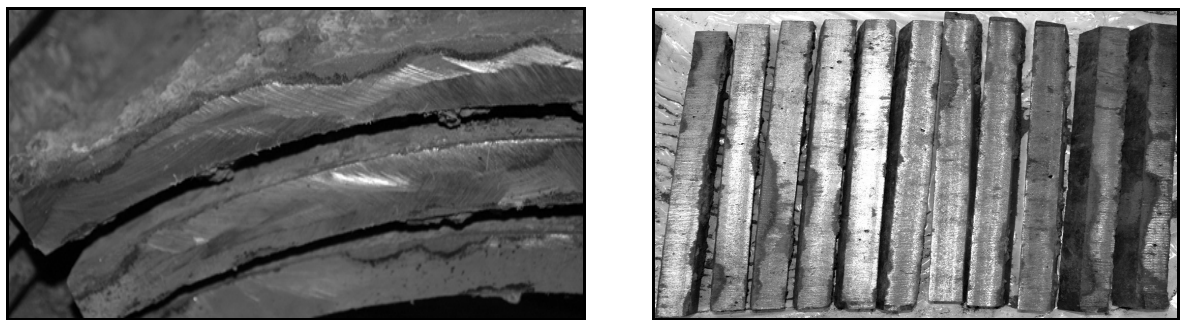

Fig. 1. Material from Pipe C: (a) Edge view of curved sections of typical plates cut from pipes (b) Rectangular bars cut from a plate and used to make SENB specimens 


\subsection{Microstructural characterisation}

Metallurgical examination was carried out to verify that each of the pipes was a grey cast iron and to determine its detailed metallographic microstructure. Metallurgical samples of the full pipe wall thickness were cut from each pipe, mounted in conducting Bakelite and polished following a typical schedule to give a $0.25 \mu \mathrm{m}$ surface finish. The microstructures of the samples were then studied using a Zeiss Axiophot optical microscope. Initially, the samples were studied in the "as-polished" condition; the samples were then etched with $2 \%$ Nital (a solution of nitric acid in methanol) and re-examined to determine the area percentage of each phase present in the matrix using Zeiss Axiophot image analysis software.

\subsection{Fracture toughness testing}

A single edge notch beam (SENB) configuration was chosen for the fracture testing (Fig. 2). Bars of rectangular cross section were cut from the plates taken from ex-service failed mains so that the span, $S$ (which was parallel to the length of the pipe), was at least $100 \mathrm{~mm}$. The full depth (wall thickness) of the plates was used to prepare the test samples, but the specimens were machined to remove the surfaces, thereby rendering the samples flat and removing any (surface) corrosion product. The machining reduced the sample depth by up to $2 \mathrm{~mm}$. A notch, nominally one third of the depth of the specimen (i.e. $7-10 \mathrm{~mm}$ ) was machined into each specimen and fatigue pre-cracking was then carried out. A load shedding method was adopted to obtain a crack growth rate of the order of $10^{-3} \mathrm{~mm} /$ cycle during fatigue pre-cracking and in this way a crack was grown from the tip of the machined notch until it extended around $2 \mathrm{~mm}$ from the tip. Typically it was possible to grow a pre-crack at a cyclic load corresponding to $\Delta K$ values of around $10-12 \mathrm{MN} / \mathrm{m}^{3 / 2}$. After pre-cracking, the test was stopped and photomicrographs were taken in order to determine the exact length of 
the generated crack. Specimens were then loaded to failure in three-point bending in an Instron $6025(5500 \mathrm{R})$ at a loading rate of $10 \mathrm{kN} / \mathrm{min}$, following the requirements of ASTM E1820-01 throughout. The apparent fracture toughness, $K_{c}$, was calculated from the critical load, $P$, corresponding to $5 \%$ secant departure from linearity on the load-displacement curve according to (see e.g. [7]):

$$
K_{c}=\frac{P S}{B W^{3 / 2}} f(a / W)
$$

In equation (1), $S$ denotes the span of the sample, $B$ and $W$ are the thickness and the depth of the specimen respectively, and $f(a / W)$ is given by:

$f(a / W)=\frac{3(a / W)^{1 / 2}}{2(1+2 a / W)(1-a / W)^{3 / 2}} \times\left[1.99-(a / W)(1-a / W)\left(2.15-3.93 a / W+2.7 a^{2} / W^{2}\right)\right]$

where $a$ is the crack length.

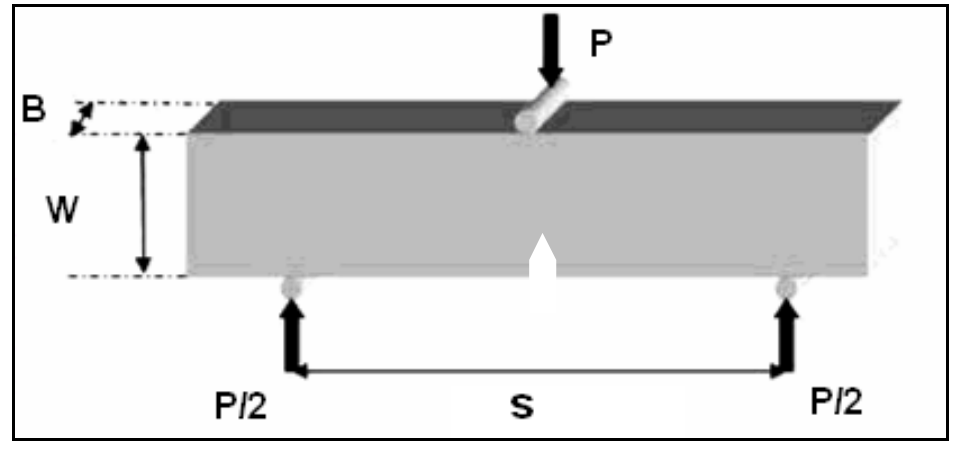

Fig. 2. Schematic of SENB test configuration

Three specimens were tested from each of the four pipes in order to determine the fracture toughness values. The thickness of the specimens, $B$, varied somewhat (see results), but the ratio of $W / B$ was in the range $1<W / B<2$, as required by the standard. For plane strain conditions, the minimum breadth of the specimens should meet the requirement of $B>$ $2.5\left(K_{I C} / \sigma_{Y S}\right)^{2}$ where $K_{I C}$ is fracture toughness and $\sigma_{Y S}$ is yield stress. The extent to which this condition was met is considered in section 3.2. 


\subsection{Fatigue testing}

Fatigue testing was carried out using a servo-hydraulic Instron 8511 with an automatic data logging system. A three point bending method was employed with a cyclic stress ratio of 0.1 and the loading frequency was $5 \mathrm{~Hz}$, with the requirements of ASTM E647-86a-00 followed throughout. Specimens were pre-cracked prior to testing (as described in section 2.3). A load shedding method was then adopted to obtain a crack growth rate of the order of $10^{-5} \mathrm{~mm} / \mathrm{cycle}$ at the outset of the fatigue tests. To achieve this, a $\Delta \mathrm{K}$ value of $8-10 \mathrm{MN} / \mathrm{m}^{3 / 2}$ was required. Initiation and growth of cracks was observed with the aid of a travelling optical microscope. Crack growth was also monitored with crack propagation sensors (CPA01, VISHAY Measurements Group). Fatigue tests continued until specimen failure. The crack length data, as a function of number of cycles, were fitted mathematically using exponential functions. This enabled the crack growth rate to be determined as a function of crack length and load level (and hence stress intensity factor) and so Paris-type plots could be produced.

\section{Results and Discussion}

\subsection{Microstructure analysis}

Optical microscopy reveals differences in the microstructures of the samples taken from the various pipes. The microstructures from all pipes show a multiphase matrix of pearlite, ferrite, and phosphide eutectic with slightly different graphite flake morphologies. Typical photomicrographs representing the microstructures seen in samples from each pipe are presented in Fig. 3. A summary regarding the graphite morphology (type, size, and form, following ASTM A247-98) is presented in Table 2. The chemical composition of the samples was determined using Energy Dispersive X-Ray spectroscopy (EDX) and is given along with the percentages of the phases present in microstructure in Table 3. 
Table 2 Graphite morphologies of the four pipes examined

\begin{tabular}{|l|l|l|l|l|l|l|l|l|}
\hline & \multicolumn{3}{|c|}{ The edges } & \multicolumn{5}{|c|}{ The mid section } \\
\hline & type & Distribution & $\begin{array}{l}\text { size } \\
\text { class }\end{array}$ & $\begin{array}{l}\text { Maximum } \\
\text { flake size/ mm }\end{array}$ & type & Distribution & $\begin{array}{l}\text { Size } \\
\text { class }\end{array}$ & $\begin{array}{l}\text { Maximum } \\
\text { flake size/ mm }\end{array}$ \\
\hline Pipe A & VII & $\begin{array}{l}\text { Between A } \\
\text { (Random } \\
\text { orientation) and B } \\
\text { (Rosette) }\end{array}$ & 3 & $\begin{array}{l}\text { Between A } \\
\text { (Random } \\
\text { orientation) and B } \\
\text { (Rosette) }\end{array}$ & VII \\
\hline Pipe B & VII & $\begin{array}{l}\text { A (Random } \\
\text { orientation) }\end{array}$ & 2 & 0.3 & VIJ & $\begin{array}{l}\text { A (Random } \\
\text { orientation) }\end{array}$ & 2 & 0.45 \\
\hline Pipe C & VII & B (Rosette) & 2 & 0.4 & VII & B (Rosette) & 2 & 0.9 \\
\hline Pipe D & VII & B (Rosette) & 3 & 0.3 & VII & B (Rosette) & 2 & 0.4 \\
\hline
\end{tabular}

Table 3 Chemical composition of the four pipes examined (wt\%)

\begin{tabular}{|l|c|c|c|c|c|c|c|c|c|c|c|}
\hline & $\mathbf{C}$ & $\mathbf{S i}$ & $\mathbf{P}$ & $\mathbf{S}$ & $\mathbf{M n}$ & $\mathbf{V}$ & $\mathbf{M o}$ & $\begin{array}{c}\text { Graphite } \\
\%\end{array}$ & $\begin{array}{c}\text { Pearlite } \\
\%\end{array}$ & $\begin{array}{c}\text { Ferrite } \\
\%\end{array}$ & $\begin{array}{c}\text { Cementite } \\
\%\end{array}$ \\
\hline Pipe A & 3.23 & 2.70 & 0.60 & 0.12 & 0.60 & 0.08 & & 17 & 50 & 25 & 8 \\
\hline Pipe B & 2.75 & 2.35 & 1.20 & 0.08 & 0.50 & 0.09 & & 18 & 24.5 & 47 & 10.5 \\
\hline Pipe C & 3.20 & 2.36 & 0.35 & 0.2 & 0.70 & 0.05 & 0.01 & 14 & 69 & 10 & 7 \\
\hline Pipe D & 3.01 & 1.50 & 0.40 & 0.08 & 0.80 & & 0.01 & 13 & 81. & 2.5 & 3.5 \\
\hline
\end{tabular}

Formatted Table

Deleted: IIV

Deleted: IIV

Deleted: IIV

Deleted: IIV

Deleted: IIV

Deleted: IIV

Deleted: IIV

Deleted: IIV 


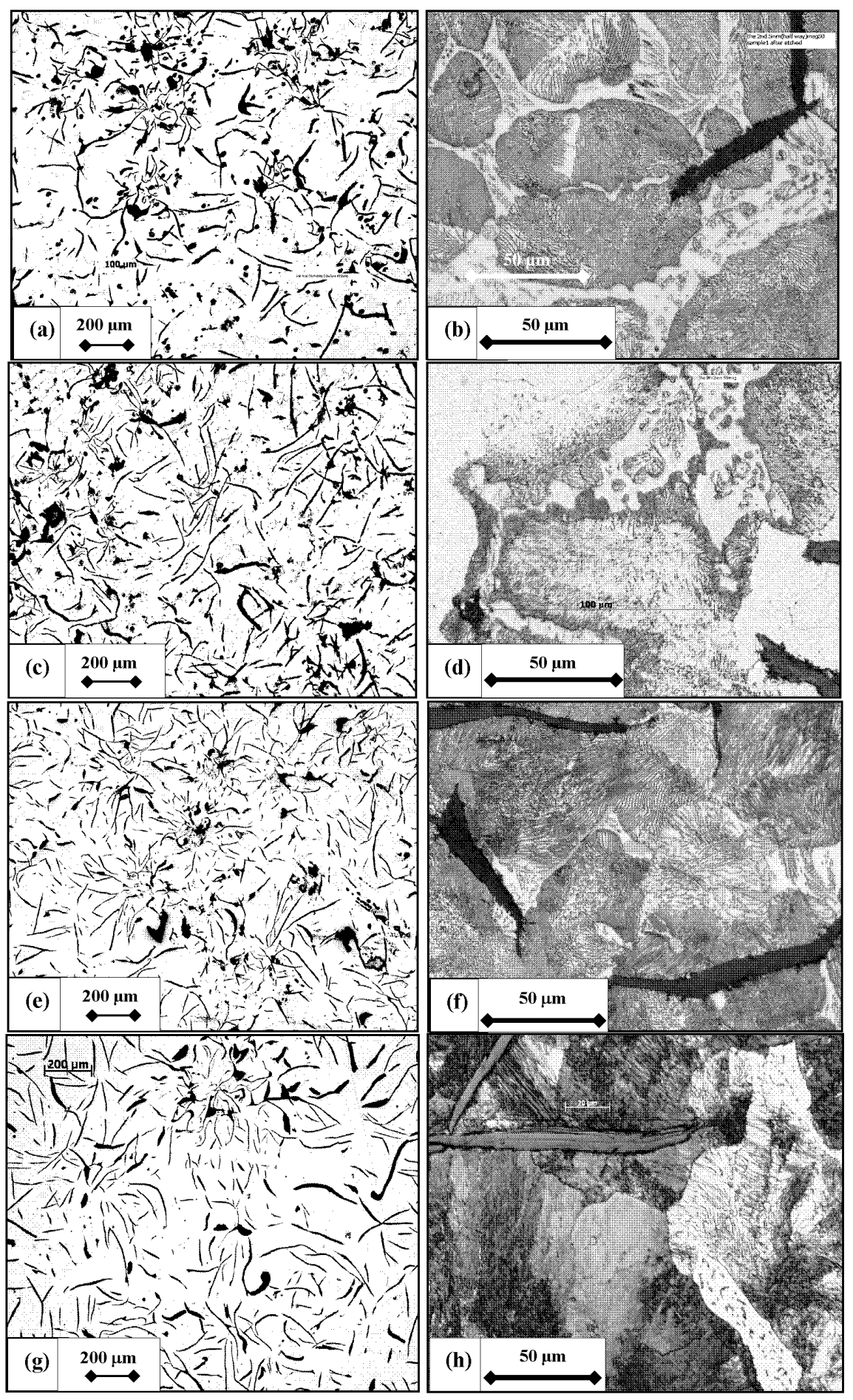

Fig. 3. Photomicrographs representing the morphologies seen in the bulk of Pipes A, B, C, and D, (a) mixture of type A 'random orientation' and type B 'rosette' graphite morphology observed in Pipe A, (b) detail of a, (c) type A 'scythe/sickle' graphite morphology observed in Pipe B, (d) detail of c, (e) type B 'rosette' graphite flake morphology observed in Pipe C, (f) detail of e, (g) type B 'rosette' graphite flake morphology observed in Pipe $\mathrm{D}$, (h) detail of $\mathrm{g}$ 


\subsection{Fracture toughness tests}

Fig. 4 shows typical load-crosshead displacement data during a fracture toughness test for one specimen from each of the four pipes investigated. Fig 5 shows the associated apparent fracture toughness values (based on the load value corresponding to a 5\% secant offset) for all specimens plotted as a function of specimen thickness (Fig. 5a) and normalised crack length (Fig. 5b). The mean values measured for Pipes A, B, C, and D were 17.0, 16.6, 18.1, and 24.3 MN $/ \mathrm{m}^{3 / 2}$ respectively. The different (mean) toughness values are consistent with the different microstructures of the cast irons in that Pipe D, which has the highest pearlite content, has the highest value. The extent to which these are true plane strain fracture toughness values can be explored using the thickness criterion. Taking $150 \mathrm{MPa}$ as a representative strength $\left(\sigma_{Y S}\right)$ for cast iron, this criterion would require $B>25 \mathrm{~mm}$ when $K_{I C}=15 \mathrm{MN} / \mathrm{m}^{3 / 2}$ and $B>69 \mathrm{~mm}$ when $K_{I C}=25 \mathrm{MN} / \mathrm{m}^{3 / 2}$. This means that the fracture toughness values, for Pipe D in particular, should be viewed with a certain amount of caution. It is interesting to note, however, that there is no clear trend for any of the materials with either crack length or specimen thickness and that the repeated tests give consistent data.

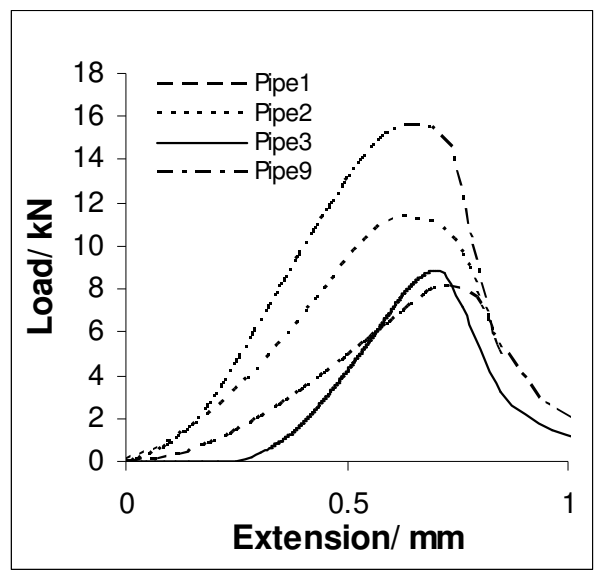

Fig. 4. Typical load-extension data during fracture tests on specimens from each of the four pipes 

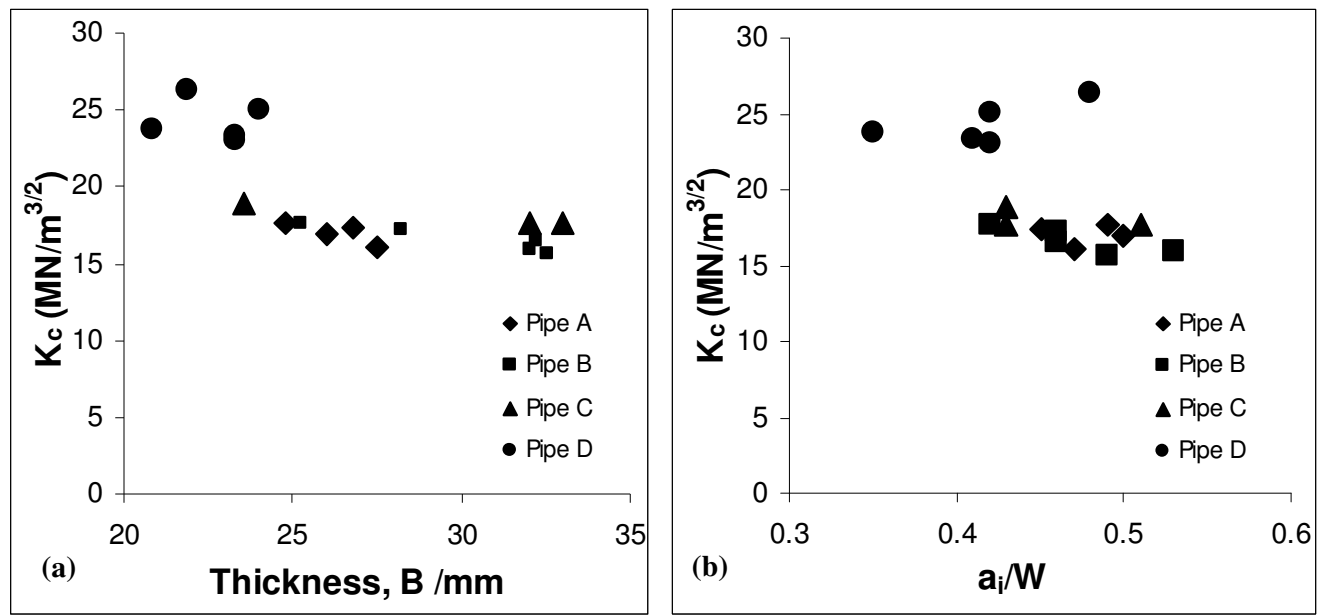

Fig. 5. Fracture toughness data for test specimens from each the four pipes investigated as a function of: (a) Specimen thickness, $B$, (b) Normalised crack length, $a_{i} / W$

\subsection{Fatigue results}

Fig. 6 is a typical plot of crack length as a function of number of cycles and the associated curve fit using the mathematical software Originpro version 8. Similar plots were obtained for all tests and the fitted curves showed high coefficients of correlation with the data.

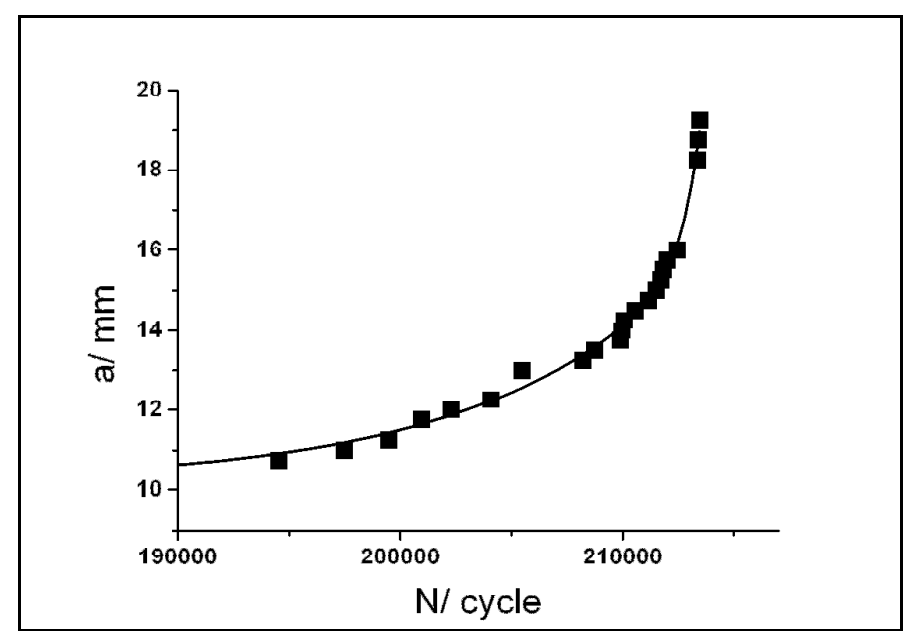

Fig. 6. Plot of crack length as function of number of cycle for a specimen from pipe $D$

The crack growth rate versus applied stress intensity factor range for all specimens is presented in Fig. 7. Fig. 7a shows the data obtained in the current study, while Fig. 7b enables these data to be compared with results from previous studies in the literature. 

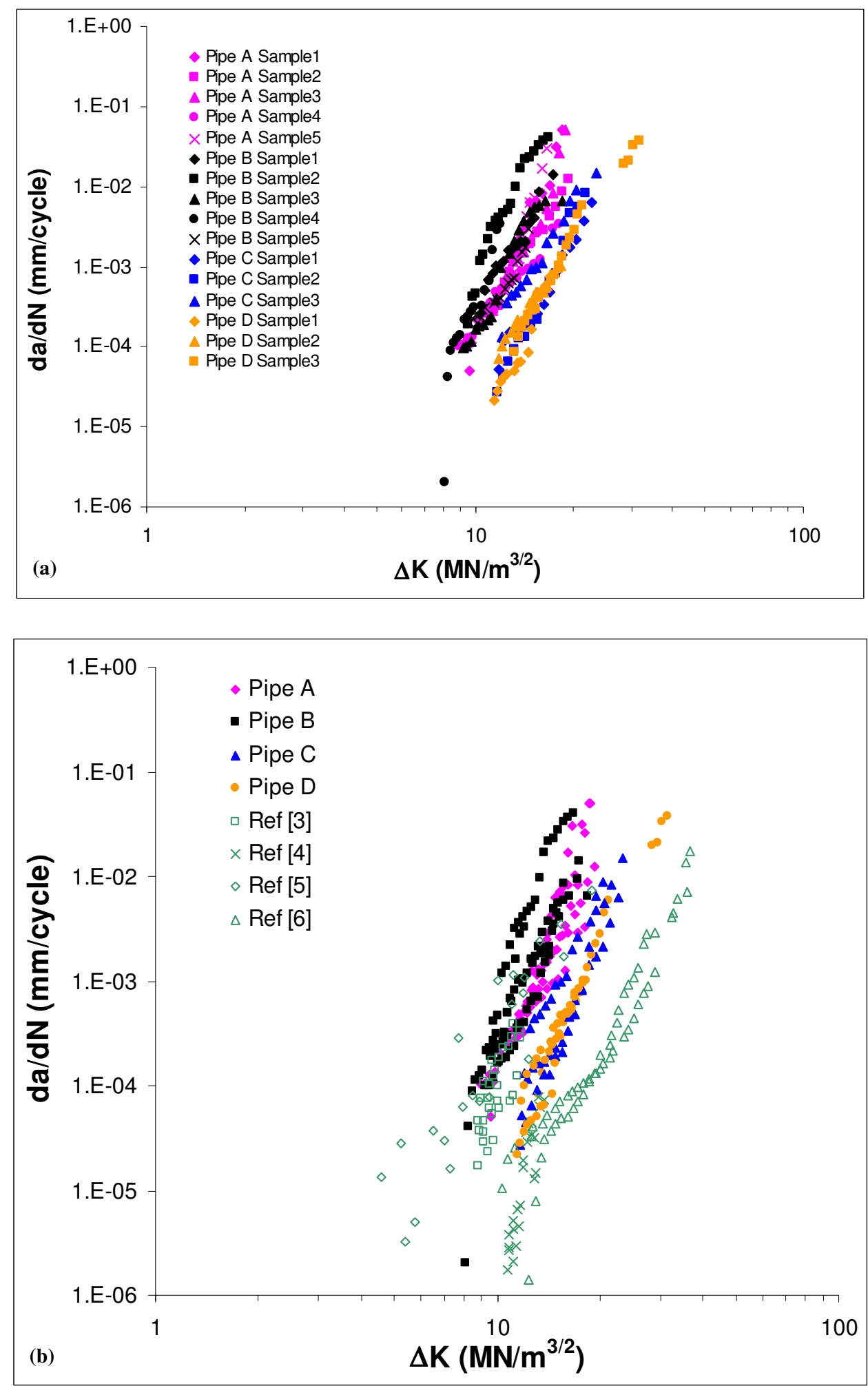

Fig. 7. Crack growth rate $(\mathrm{d} a / \mathrm{d} N$ as a function of $\Delta K)$ : (a) specimens from pipes A-D, (b) specimens from pipes A-D compared with data from Refs. [3-7] 
Looking first at Fig. 7a, there is perhaps a trend of the Paris plots being displaced to the right with increasing fracture toughness. This is consistent with other results in the literature. Hornbogen [6] shows that crack growth data for a relatively tough cast iron with a spheroidal graphite morphology lie to the right of data for a relatively less tough cast iron with graphite flake morphology. The data in Fig. 7a indicate that in the tougher pipes there is stable fatigue crack growth at stress intensity factor ranges which lead to a peak stress intensity factor that exceeds the fracture toughness data reported in the previous section. It is suggested that this is because the $5 \%$ offset method leads to a value of the fracture toughness which is a reasonable approximation to a plane strain value, while the fatigue sample is subject to increasing dominance of plane stress conditions as the crack length increases, and thus can sustain higher apparent stress intensity factors. Fig. $7 \mathrm{~b}$ compares the crack growth data from the present study with previous results from the literature for cast irons with nominally similar flake graphite morphologies. The data are generally in good agreement, although the data from reference [6] lie well to the right. Interestingly the fracture toughness values reported for the samples tested in reference [6] are higher than for any of the cast iron tested in the present work and there are differences of detail in the microstructure.

\subsection{Observations on Crack Growth Mechanisms}

Fig. 8 presents photomicrographs, which illustrate various aspects of the crack growth behaviour during fatigue testing. There is evidence that the crack growth mechanism varies during the fatigue life, corresponding to different regions on the Paris representation of the fatigue data. At low applied stress intensity factor range (near the threshold for crack growth), there is a tendency for crack branching, Fig. 8a, and for dispersed cracking ahead of the crack tip, influenced very much by the graphite flakes, Fig. $8 \mathrm{~b}$. As the crack grows, the mechanism of the crack growth can still be described as the coalescence of microcracks 
forming around the graphite flakes generally along an intergranular path. With further increase in crack length, and associated increase in $\Delta K$ (and larger crack tip plastic zone), a dominant mode I crack is apparent, Fig. 8c. In this region the crack follows a combination of intergranular and transgranular path, Fig. 8d. The overall fracture surfaces for all the specimens were macroscopically flat, i.e. the crack grew in a planar manner with respect to the original notch. Examining the fracture surface with the unaided eye and favourable illumination it was possible to discern the line on the fracture surface corresponding to the transition between sub-critical fatigue crack growth and the (catastrophic) fast fracture. Fig. 9 shows one face of the fracture for a specimen from Pipe C. Scanning electron microscopy was used to examine the different regions of crack growth in more detail. Fig. 10 shows photomicrographs corresponding to sub-critical fatigue crack growth, Fig. 10 (a-b), and fast fracture, Fig. 10 (c-d). While the images are similar in appearance, it can be argued that the fatigue region shows more flat facets in a manner which is consistent with a greater proportion of intergranular crack path during fatigue crack growth. This can be compared to the final failure (fast fracture), which is more transgranular. In this latter mechanism the crack does not follow a preferential path and hence crack growth occurs via the coalescence of graphite flakes by either a transgranular or an intergranular induced path or some combination of the two. 


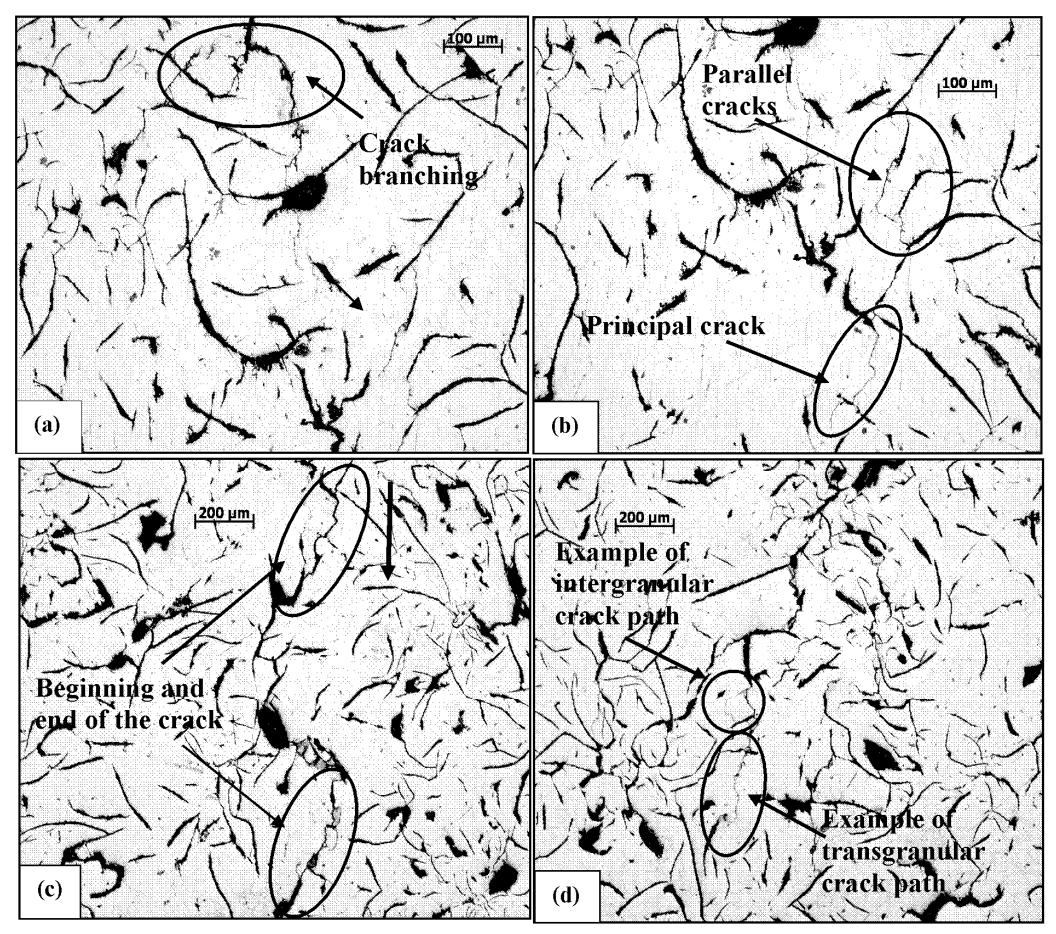

Fig. 8. Photographs of the surface of a SENB fatigue specimen from Pipe $A$ after: (a) 25,000 cycles an example of the main stream crack branching, $\Delta K=10 \mathrm{MN} / \mathrm{m}^{3 / 2}$, (b) 30,000 cycles, example of the initiation of parallel cracks as $\Delta K$ increases, $\Delta K=11 \mathrm{MN} / \mathrm{m}^{1.5}$, (c) 52,500 cycles well established crack, $\Delta K=13.5$

$\mathrm{MN} / \mathrm{m}^{3 / 2}$, the ovals indicates where the crack enters and leaves, and arrow shows the direction of the moving crack, (d) 53,500 cycles, an example of both intergranular and transgranular crack path indicated by circles, high $\Delta K$ regime, $\Delta K=14.5 \mathrm{MN} / \mathrm{m}^{3 / 2}$

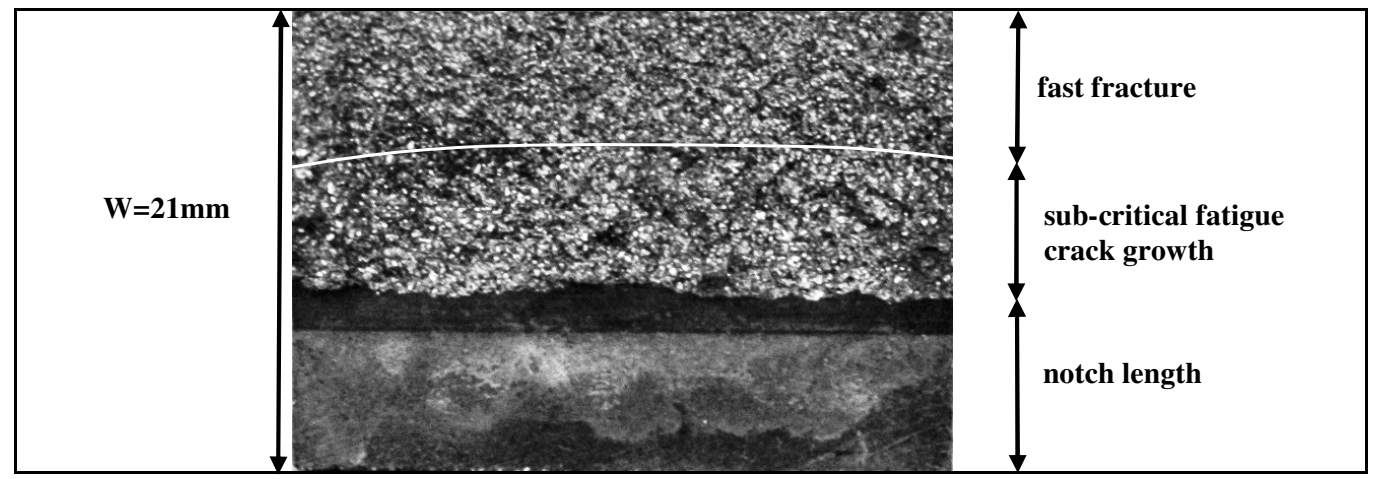

Fig. 9. Photograph of the fracture surfaces of the either side of a specimen from Pipe C. The white line indicates the transition from slow fatigue crack growth to fast fracture 


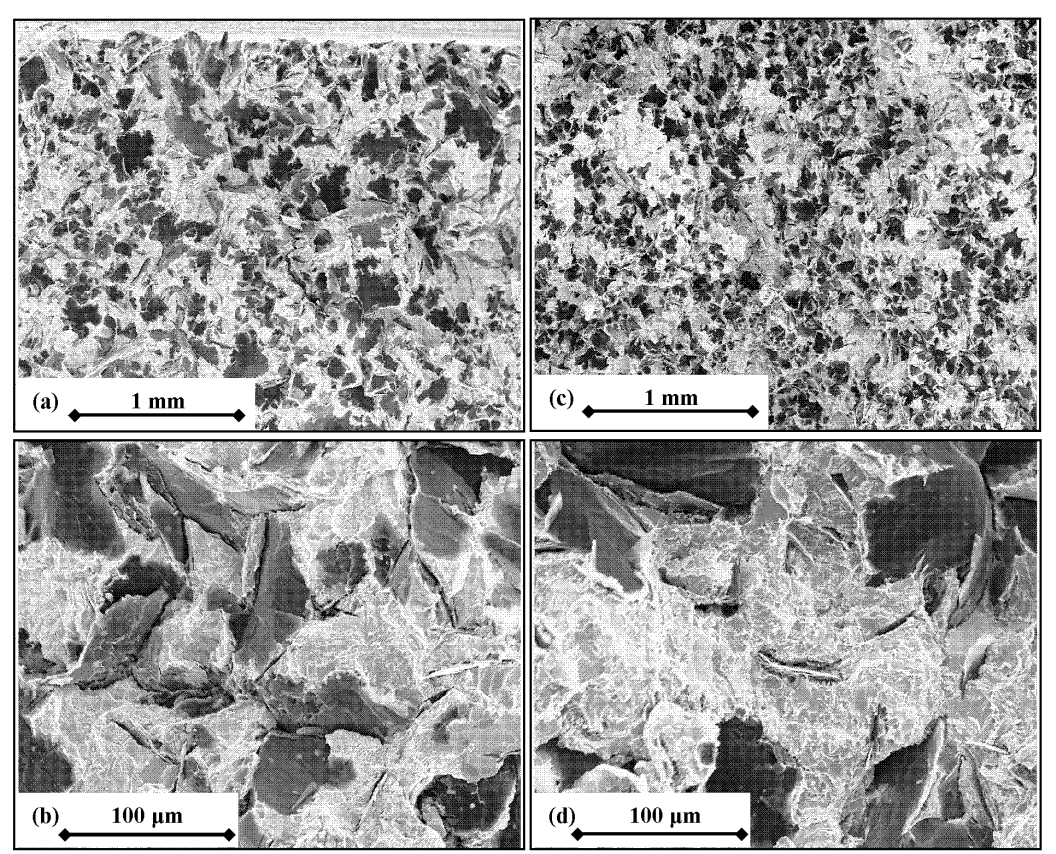

Fig. 10 SEM Photomicrographs for a sample from Pipe C: (a) fracture surface within region of sub-critical fatigue crack growth, (b) detail of (a), (c) fracture surface within region of fast fracture, (d) detail of (c)

\section{Application of Paris relation to model $S$ - $N$ behaviour of water mains}

The Paris relation from the fatigue testing was used to develop a simple $S$ - $N$ model for specimens from a pipe subjected to a bending load. The fatigue crack growth behaviour of the material is given by the Paris relation as:

$$
\frac{d a}{d N}=A \Delta K^{m}
$$

where:

$$
\Delta K=K_{M A X}-K_{M I N}
$$

and $A$ and $m$ are the Paris constants. The stress intensity factor, $K$, for a SENB specimen geometry was calculated using equations (1) and (2) presented in 2.3. The Paris constants for the different pipe materials were obtained from the relevant $\mathrm{d} a / \mathrm{d} N-\Delta K$ plot and averaged for each pipe; the values are given in Table 4 . The number of cycles to failure, $N_{f}$, for each pipe 
was obtained by using MATLAB to integrate the Paris relation numerically from an assumed initial crack length, $a_{i}$, up to the crack length at which fast fracture occurs, $a_{f}$, calculated on the basis of the measured fracture toughness:

$$
N_{f}=\int_{a_{i}}^{a_{f}} \frac{d a}{A(\Delta K)^{m}}
$$

In this way, the $S-N$ plots obtained from the integration of Paris equation are based on the assumption that pipes already contain initial flaws which are either inherent or arise during service. Cast iron pipes most commonly suffer from localised corrosion such as corrosion pits. These corrosion pits can be regarded as flaws and hence estimating the remaining inservice fatigue life of the pipe becomes of great importance.

Table 4 Paris constants for Pipes A-D, derived from experimental data

\begin{tabular}{|c|c|c|}
\hline Pipe & $m$ & $\begin{array}{c}A \mathrm{~mm} / \text { cycle } \\
\left(\times 10^{-13}\right)\end{array}$ \\
\hline $\mathrm{A}$ & 7.5 & 46 \\
\hline $\mathrm{B}$ & 8.0 & 28 \\
\hline $\mathrm{C}$ & 7.4 & 9.5 \\
\hline $\mathrm{D}$ & 7.7 & 2.1 \\
\hline
\end{tabular}

Fig. 11 presents the derived $S-N$ data for trunk mains samples. The stress shown on the vertical axis is the nominal peak bending stress. Results are shown based on two different assumptions regarding initial crack length. In Fig. 11(a) the assumed initial crack size is such that $a_{i} / W=0.0125$, giving values of $a_{i}$ in the range $0.275-0.4 \mathrm{~mm}$ (for the different values of nominal wall thickness, $W$ ); this is the same order of magnitude as the graphite flake size and is thus representative of an inherent material defect. In Fig. 11(b) the assumed initial crack size is such that $a_{i} / W=0.2$, giving values of $a_{i}$ in the range $4.4-6.4 \mathrm{~mm}$ (for the different values of wall thickness, $W$ ); this is perhaps representative of a large initial defect (e.g. a manufacturing defect) or of the effect of corrosion in service. 

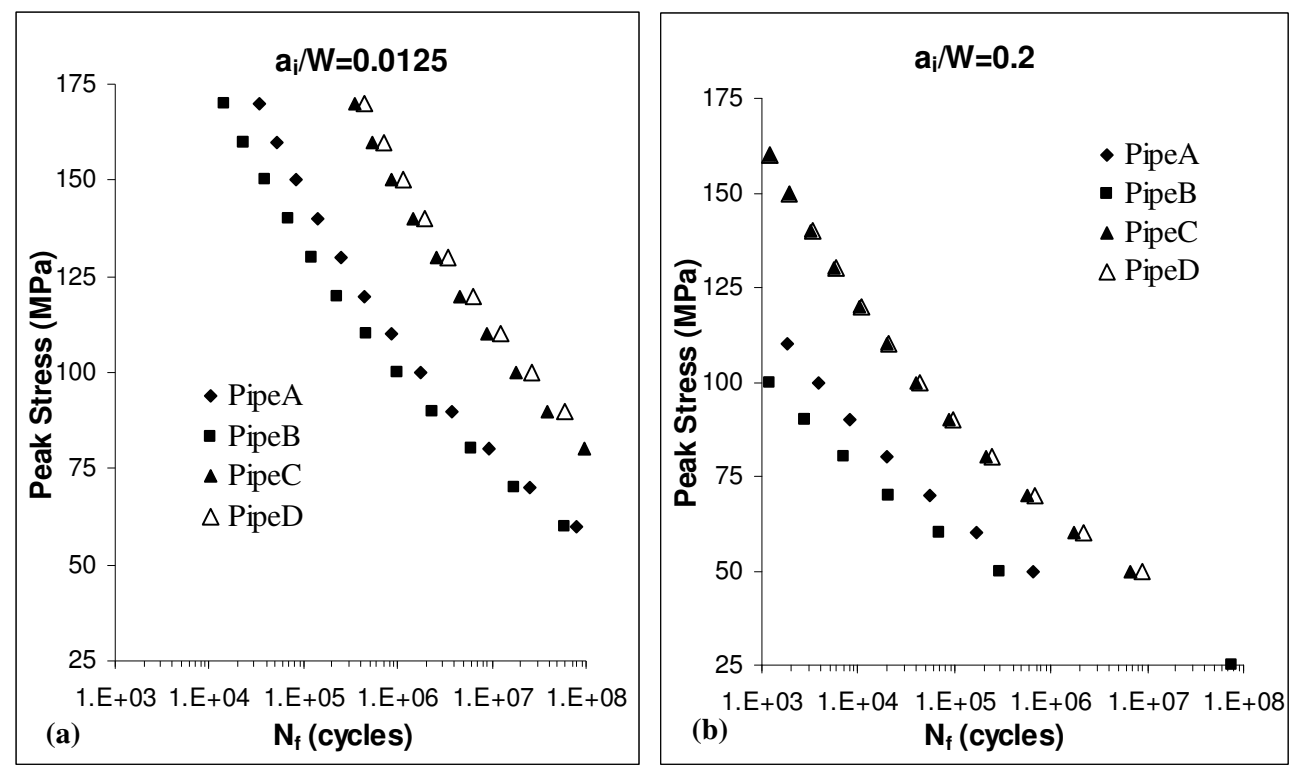

Fig. 11. Calculated $S$ - $N$ curves for pipe A-D: (a) the initial flaw size is small (the order of microstructural features and (b) the initial flaw size is large - i.e. one fifth of the thickness of the pipe wall

Fig. 11a shows that at modest levels of applied stress (75 MPa), samples from all four pipes are expected to show a fatigue life of approximately $10^{7}-10^{8}$ cycles and that Pipes C and D perform better than Pipes A and B. The same trend of material performance is apparent in Fig. 11b, but in this case the lives are considerably shorter as a result of the larger assumed initial crack length.

In previous work [8], $S-N$ data were presented for ex service cast iron distribution main samples, of nominally $10 \mathrm{~mm}$ by $12.4 \mathrm{~mm}$ (full wall thickness) cross-section, tested in three point bending. The Paris law determined in the present work can be used to model these data. The distribution main samples showed a 'Class A' graphite morphology and so the Paris relation for Pipe B in the present study was used in the model. Further, the sets of distribution mains samples were from pipes identified as being in "good condition" (material reference B30.28), "corroded" (B22.14) or "heavily corroded" (B22.03). For the purposes of the Paris approach, this means that the sample sets will have different initial flaw sizes. The data from ref. [8] and the results from the integration of the Paris model are shown in Fig. 12. 
The behaviour of the samples in relatively good condition (not corroded) can be described reasonably well using an initial crack length of $1.0 \mathrm{~mm}$, which may relate to an aspect of the microstructure (or minor influence of corrosion), while the behaviour of the other samples is captured reasonably well using larger defect sizes, $2.8 \mathrm{~mm}$ and $4.3 \mathrm{~mm}$ for the "corroded" and "heavily corroded" samples respectively, which reflect the effect of the service induced corrosion. These dimensions appear reasonable when compared with the depth of corrosion apparent from looking at the fracture surfaces of samples from these pipes, see Fig. 4 ref. [8]. While these calculations are inevitably approximate, it is argued that this demonstrates a degree of consistency between the predicted data and those of the literature, giving confidence in formulating any fatigue performance assessment tool for the pipes based on the microstructural variation (graphite morphology) and the associated Paris relation.

This section has demonstrated that the crack growth data can be used to make calculations of fatigue life for samples from cast iron water pipes, both from trunk mains and distribution mains. The high value of the Paris exponent, $m$, may mean that in practice the role of fatigue crack growth in service is limited, because cracks will not grow at any appreciable rate until they are close to being at the critical crack length. Further consideration of the origin of defects and the loading in service is needed before any definitive conclusions may be drawn. 


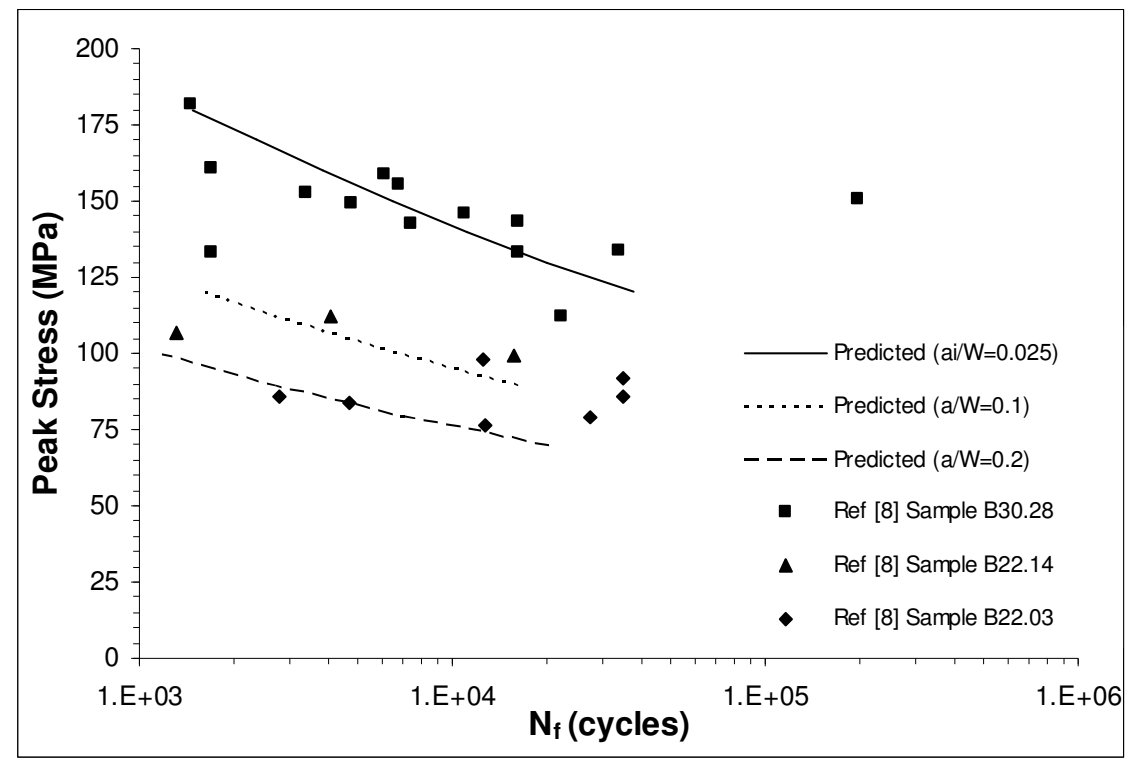

Fig. 12. Comparison plot of stress versus number of cycle to failure for literature [8] to those predicted by the model presented in this paper

\section{Concluding remarks}

The present work has demonstrated that the fracture toughness and fatigue behaviour of cast iron used in the water industry shows a range of behaviour dependent on the details of the microstructure. Data have been presented relating to the fracture toughness and the Paris relations for a representative range of cast irons and the associated role of microstructure. Integration of the Paris relation has been used to demonstrate the role of initial defects and of defects that may arise in service (from corrosion) on fatigue life and this has been correlated with previously published data for laboratory tests on specimens from distribution mains. Further work is needed to understand whether the defect sizes and stress levels seen in service are such that fatigue is likely to be a significant contributory factor to failure of trunk mains. Another important area for investigation is the role of microstructure on the corrosion behaviour. 


\section{Acknowledgements}

The authors would like to thank Mr Antony Scratt (Struers Ltd), Mr Anton Chitty (VISHAY measurement groups Ltd UK) and colleagues at the University of Surrey, especially Mr. Peter Haynes and Mr. Mike Parker, for their assistance and technical advice. The authors would like to acknowledge the support of Thames Water Utilities Ltd during the course of this investigation, which is part of a wider study of cast iron trunk mains in collaboration with NRC (Canada). It is a pleasure also to acknowledge many helpful discussions with Mr Nic Clay-Michael, Mr Jeff Farrow, Dr Hal Belmonte and Dr Tim Evans of Thames Water and Dr Balvant Rajani of NRC.

The opinions expressed in this paper are those of the authors and not necessarily endorsed by the University of Surrey or Thames Water Utilities Ltd.

\section{References}

1. B.Rajani and J.Makar, "A methodology to estimate remaining service life of grey cast iron water mains”, Canadian Journal of Civil Engineering, 27 (2000), 1259-1272.

2. K.Atkinson, J.T.Whiter, M.Mulheron and P.A.Smith, "Failure of small diameter cast iron pipes”, Urban Water, 4(2002), 263-271.

3. P.Baicchi, L.Collini, and E.Riva, "A methodology for the fatigue design of notched casting in grey cast iron", Engineering Fracture Mechanics, 74 (2007), 539-548.

4. M.N.James and.Wenfong $\mathrm{Li}$, "Fatigue crack growth in austempered ductile and grey cast ironstress ratio effect in air and mine water", Materials Science and Engineering A, 265 (1999), 129-139.

5. B.M.Kapadia and E.J.Imhof, Jr., "Fatigue crack growth in cast iron and cast steel", Cast Metals for Structure and Pressure Containment Application in App1, ASME-MPC-11, December, 1979

6. Erhard Hornbogen, "Fracture toughness and fatigue crack growth of grey cast irons", Journal of Materials Science, 20 (1985) 3897-3905

7. Richard W. Hertzberg, Deformation and Fracture Mechanics of Engineering Materials, $4^{\text {th }}$ edition (1996), Wiley

8. H.M.S.Belmonte, M.Mulheron and P.A.Smith, "Some Observations on the Strength and Fatigue Properties of Samples Extracted from Cast Iron Water Mains", Fatigue and Fracture of Engineering Materials and Structures, in press (2009). 